\title{
Fruits' Nutrient Composition and Their Influence on Consumption by Chimpanzees in Kalinzu Forest, South Western Uganda
}

\author{
Grace Kagoro-Rugunda \\ Department of Biology, Faculty of Science, Mbarara University of Science and Technology, Mbarara, Uganda \\ Email: kgraceug2002@must.ac.ug, kgraceug2002@yahoo.co.uk
}

How to cite this paper: Kagoro-Rugunda, G. (2020) Fruits' Nutrient Composition and Their Influence on Consumption by Chimpanzees in Kalinzu Forest, South Western Uganda. Open Journal of Ecology, 10, 289-302. https://doi.org/10.4236/oje.2020.105018

Received: April 25, 2020

Accepted: May 25, 2020

Published: May 28, 2020

Copyright (๑) 2020 by author(s) and Scientific Research Publishing Inc. This work is licensed under the Creative Commons Attribution International License (CC BY 4.0).

http://creativecommons.org/licenses/by/4.0/

\section{(c) (i) Open Access}

\begin{abstract}
This study determined the influence of nutritional fruit content on their consumption by chimpanzees in Kalinzu forest. Fruits consumption frequencies were obtained from analysis of chimpanzee faecal samples picked over a period of two years. Fruit content was analyzed using freeze dried fresh samples using standard techniques. Musanga leo-errerae (76.14\%), Ficus spp $(66.05 \%)$ and $(18.68 \%)$ were the most commonly eaten fruits of all faecal samples $(\mathrm{N}=2683)$. Generally, fruit consumption increased for fruits with total phenols and tannins below 1\% per gram except for Musanga leo-errerae, Uvariopsis congoensis and Aframomum angustifolium. Multiple regression revealed that of the 15 nutrient parameters investigated, only calcium, tannins, crude fat, protein and energy content of the fruits that constitute the major food components for basic animal body needs and functioning of energy, body building and a healthy skeleton significantly predicted $76.86 \%$ of consumption $\left(R^{2}=76.86 \% ; P=0.019\right)$. However, the fact that some of the most eaten fruits like Aframomum angustifolium and Musanga leo-errerae were recorded to have the highest amounts in tannins shows that there must be additional factors into play. Other than fruit availability, consideration of effect of fruit size and handling within the existing models of chimpanzees' diet could hence enhance further the understanding of fruit consumption.
\end{abstract}

\section{Keywords}

Chimpanzees, Fruit Consumption, Fruit Nutrients, Kalinzu

\section{Introduction}

The plants world on which animals feed is biochemically complex. This bio- 
chemical diversity of plants in a number of ways influences their consumption by animals. Nutrient parameters are among the most important influences on primate food choice [1]. Selectivity of fruit should optimize foraging efficiency by maximizing the nutritional value, particularly the energy or protein, and minimize or enhance avoidance of plant secondary anti-nutrients and toxins [2]. Numerous nutritional studies of folivorous non-human primates have revealed that protein content is positively correlated with food selection and, conversely, that fibre and condensed tannin content are negatively correlated with food selection. Only a few nutrition-oriented studies on fruit selection in frugivorous chimpanzees have been conducted [3] [4]. Most research on comparative nutrition in Apes has been carried out between plants eaten and plants not eaten to determine whether the differences in nutrient and non-nutritional content can explain such a selectivity or choice of consumption [5] [6]. In this study, comparison was made of the nutrient and non-nutritional content of fruits eaten in high and least frequencies in Kalinzu where fruit availability alone could not explain the difference in consumption selectivity [7]. Identifying nutritional components of fruits eaten by chimpanzees is critical not only for understanding of the fruit chemistry and toxicology, but also to discover how these contents may influence fruit selection and consumption by chimpanzees in Kalinzu Forest. As stated by Fashing [1], an important goal in nutritional ecology is to understand what governs the diet selection of free-living animals.

\section{Methods and Materials}

\subsection{Study Site}

The fruit species analyzed were obtained from the chimpanzee M-group ranging area of Kalinzu forest reserve (Figure 1). This forest reserve is located in south western Uganda $\left(0^{\circ} 17^{\prime} \mathrm{S}\right.$ and $\left.30^{\circ} 07^{\prime} \mathrm{E}\right)$ at an altitude ranging from 700 to $1840 \mathrm{~m}$ above sea level [8] [9]. It forms a pocket of forest remnants on the western $\mathrm{Al}$ bertine rift valley escarpment and is classified as a medium altitude moist evergreen forest with a chimpanzee population of 230 individuals [10]. Other diurnal primates found in this forest include Papio anubis, Colobus guereza, Cercopithecus ascanius, Cercopithecus I'hoesti and Cercopithecus mitis [8].

\subsection{Data Collection Methods}

\subsubsection{Fruit Consumption Determination}

The primary source of data on fruit consumption frequency was obtained from analysis of 2683 faecal samples collected over a period of two years in Kalinzu forest reserve. Daily follows for 6 to 10 hours per day of the M group chimpanzees were made and during these follows, freshly deposited faecal samples were picked and preserved in 100\% ethanol, and analysis done on a monthly basis. Fruit consumption frequency for each fruit species was calculated as percent presence of the fruit item in all feacal samples. 


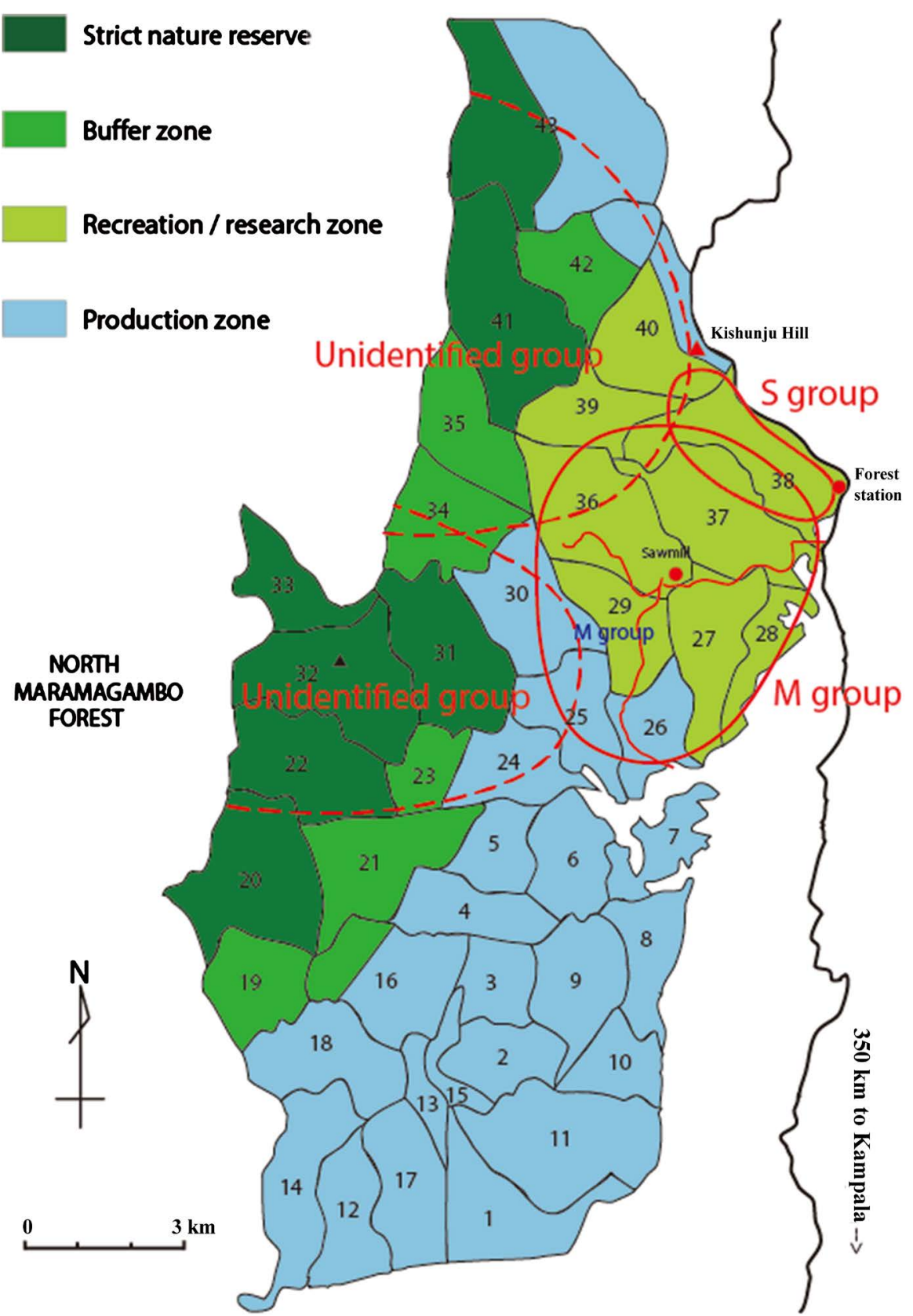

Figure 1. Map of Kalinzu forest Reserve showing the Chimpanzee M-group ranging area.

\subsubsection{Plant/Fruit Collection and Preparation for Content Analysis}

Plant species identified to be included in the selected nutritional content analysis were purposively collected as documented from faecal analysis from 2010 to 2012. Fruit samples were collected from plants that were visited by chimpanzees in their ranging habitat after they left or from a patch within the same transect similar in phenophase and identified by Makerere University Herbarium. All these plants were collected within the home range of the M-group of chimpanzees. Overall, 15 species of fruits were collected. Fruit samples were freeze-dried at the Institute for Zoo and Wildlife Research (IZW), Berlin, for 72 hours until constant weight was attained. All dried samples were finely ground prior to 
analysis with an IKA A11 basic mill (IKA, Staufen, Germany) and passed through a $1 \times 1 \mathrm{~mm}$ sieve.

\subsubsection{Nutritional Content Analysis}

Macro nutritional and mineral analyses of the fruit samples were done in the nutritional laboratory of Leibniz Institute for Zoo and Wildlife Research (IZW), Berlin. Samples were analyzed using standard techniques: Nitrogen was determined by complete combustion at a temperature of $950^{\circ} \mathrm{C}$ in pure oxygen, using rapid N III analyzer (Elementar Analyzer Systeme, Hanau, Germany). The plant sample was extracted by using sulphuric acid and a catalyst. The acidic solution was neutralized with caustic soda solution $(\mathrm{NaOH})$ which leads to the production of Ammonia gas $\left(\mathrm{NH}_{3}\right)$. This gas is a transformation of the same constant volume of sulphuric acid. This was followed by back titration of the overload of sulphuric acid with caustic soda solution. Conversion of the nitrogen into protein concentration was done by multiplying with a conversion factor of 6.25. Protein $(\% \mathrm{DM})=6.25 \times$ Nitrogen [11]. Fats were extracted from the samples with Ethyl Ether using a fully automatic Soxhlett-system (Gerhardt Laboratory Systems, Konigswinter, Germany). The sample was first oven dried overnight. In the analyzer, the sample was washed with petroleum ether from which fat dissolved out and was left in the beaker. Energy content was analysed using the Bomb calorimeter which gives the gross energy of food items. For each sample, $0.5 \mathrm{~g}$ was put in the decomposition vessel to determine its calorific value by burning the sample in pure oxygen atmosphere (C5003 IKA, Staufen, Germany). The heat/energy produced was measured in $\mathrm{KJ} \cdot \mathrm{g}^{-1} \mathrm{DM}$. This was done three times for each sample and an average value obtained. The water soluble carbohydrates: Sucrose, D-glucose, D-fructose, and starch were determined with commercialized enzymatic tests (R-Biopharm, Darmstardt, Germany; UV method). The results were recorded as milligrams per kilogram and are expressed as percentage of dry matter in this manuscript. Detergent fibre analyses were performed following vanSoest [12] with Neutral detergent fibre (NDF), Acid Detergent Lignin (ADL) and Acid Detergent Fibre (ADF) fractions estimated by the ANKOM A200/220 Fibre analyzer. Samples were weighed and digested in Ankom filter bags F57 or F58 with either ADF or NDF solutions (plus Alpha Amylase and $0.08 \mathrm{M} \mathrm{Na}_{2} \mathrm{SO}_{3}$, for the latter), washed thrice in $2000 \mathrm{ml}$ boiling water (with Alpha amylase for the first two rinses of NDF fractions) and once with acetone, and weighed again to give percent ADF and NDF. Percent hemicelluloses were estimated by subtraction of ADF from NDF values [12]. The mineral elements of the different fruits were determined using the Atomic spectrophotometer.

Secondary plant compounds contents analyzed included total phenols and tannins. Analysis of total phenols and hydrolysable tannins were carried out at the Department of Animal Ecology and Conservation, Biocentre, Grendel, University of Hamburg as per the method described by Haslam [13]. Folin-Ciocalteau Method was used for Analysis of Total phenols determined by extracting $100 \mathrm{mg}$ 
of the sample in $10 \mathrm{ml}$ of water in a $100^{\circ} \mathrm{C}$ water bath for 40 minutes; after which $500 \mu \mathrm{l}$ aliquots of the filtered extract were placed in a test tube, then $500 \mu \mathrm{l}$ of Folin-Ciocalteus-prepared solution (1:1 diluted with water) was added. This was followed by addition of $9 \mathrm{ml}$ of Sodium carbonate solution (20\%) after which the extinction against water was read at $750 \mathrm{~nm}$ exactly after 6 minutes. The method is based on a redox-reaction using Beckman DU ${ }^{\mathrm{R}} 7400$ Spectrophotomerter: The coloured complex of the Folin-Ciocalteau-Reagent (yellow) was reduced at the same time the phenols would be oxidised. The solution changed in colour. Measurement of the extinction was done by a spectrophotometeric detection at 720 $\mathrm{nm}$. The total amount of phenolics was then calculated from a calibration curve prepared using Pyrogallol formula as described in [14]:

$$
\text { Total Phenolics }(\%)=\frac{\text { Extincion }+C}{\text { Sample weight }(\mathrm{mg}) * B}
$$

where $C=$ Intercept $(0.0054)$

$$
B=\text { Slope (0.008) }
$$

Tannins were determined using the Butanol-Method by extracting $50 \mathrm{mg}$ of sample in $5 \mathrm{ml}$ of methanol (50\%) for 24 hours. The extract was then filtered and diluted in a ratio of 1:10 using 50\% methanol. To $2.5 \mathrm{ml}$ of the diluted filtrate was added $2.5 \mathrm{ml}$ of tannin reagent ( $5 \mathrm{ml}$ Hydrochloric acid (37\%) in $95 \mathrm{ml}$ n-butanol), incubated for 160 minutes in an $80^{\circ} \mathrm{C}$ warm water bath, and extinction read at $540 \mathrm{~nm}$ after cooling. Percent of tannins in each sample was calculated using the formula [13]:

$$
\text { Tannins }(\%)=\frac{\text { Extincion } * 450}{\text { Sample weight }(\mathrm{mg})}
$$

\subsection{Statistical Analysis}

Fruit consumption was treated as the dependent variable while the nutritional/ non nutritional fruit contents were the dependent variables. Pearson's correlation coefficients ( $r$ ) were used to identify correlations between quality of food plants with respect to nutritional and non-nutritional quality and consumption frequencies. The multiple regression model of moderate to strongly positively correlated nutritional contents was performed between nutrient content and percent frequencies consumption of fruit to reveal significant influences of nutrient content on fruit consumption. All tests were done using Minitab 14 at 5\% level of significance.

\section{Results}

\subsection{Fruit Consumption by Chimpanzees in Kalinzu Forest}

Unlike other forests where the important food sources were Ficus sp and/or terrestrial herbaceous vegetation (THV), the diet of Kalinzu chimpanzees was dominated by two fruit genera of Musanga and Ficus. Musanga leo-errerae occurred in $76.17 \%$, Ficus sp occurred in $66.05 \%$ while Aframomum angustifolium 
occurred in $18.98 \%$ of all faecal samples $(\mathrm{N}=2683)$. The rest of the fruit species including occurred in less than $10 \%$ of the total faecal samples. Although the number of fruits eaten by chimpanzee was 23 , due to the differences in the fruit phenophases, only 15 fruit samples of the fruit eaten by chimpanzees were collected for nutrient analysis with their results as presented in Table 1.

\subsection{Nutritional Content of Fruits Eaten by Chimpanzees}

Generally, fruits eaten by chimpanzees contained considerable amount of fibre including the Neutral detergent fibre (NDF), Acid detergent fibre (ADF) and Acid detergent lignin (ADL). Chrysophyllum albidum contained the highest amount of fibre of the three fibre categories. Musanga leo errerae, a fall-back fruit and the most frequently eaten fruit by chimpanzees in Kalinzu forest was also found to contain a relatively high fibre content of $64.22 \% \mathrm{NDF}, 49.14 \%$ $\mathrm{ADF}$ and $32.18 \%$ ADL. The water-soluble carbohydrates (fructose, glucose and sucrose) (combined into one column in Table 1) were found to be highest in Aframomum angustifolium, Ficus sur and Mimsops bagshawei in that order. When looked at individually, Sucrose was generally low in all fruits ranging from $0.01 \%$ to $6 \%$ of dry matter. This means that most of the water-soluble carbohydrates were contributed to by fructose and sucrose. It is only Aframomum angustifolium that had the three water-soluble carbohydrate almost in equal amounts with fructose contributing $7.515 \%$, glucose $7.44 \%$ and sucrose $6.787 \%$. Ficus sur, the second highest in water-soluble carbohydrates was constituted with $5.508 \%$ fructose, $9.077 \%$ glucose and $0.006 \%$ sucrose while Mimsops bagshawei included $7.98 \%$ fructose, $5.14 \%$ glucose and $0.07 \%$ sucrose. The total water-soluble carbohydrate values of the other plant parts are detailed in Table 1.

There was no big variation in energy content of fruits eaten by chimpanzees. Energy content ranged from the least of $12.52 \%$ found in Aframomum angustifolium to the greatest of $24.6 \%$ found in Chrysophyllum albidum. The latter was found to have the greatest crude fat content at $17.33 \%$. Three fruits were found to also offer a reasonably good amount of protein in chimpanzee diet. These included Myrianthus holistii (18.68\%), Prunus africana (18.34\%) and Teclea nobilis (16.11\%).

In regard to the micronutrient contents, the fruit mostly consumed Musanga leo-errerae, was also found to have the highest amount of calcium and magnesium, Piper guinense had the highest amount of Potassium while Dasylettis eggelingii had the highest amount of Sodium.. Other fruits were rich in other mineral ions like Potassium in Ficus sur and Myrianthus holistii, Iron in Prunus africana and Diospyros abysinica, Copper in Myrianthus holistii and Zinc in Teclea nobilis. Myrianthus holistii fruit contained Potassium, Copper and Magnesium in high amounts therefore a great source of minerals for chimpanzees (Table 1). Total phenols' content was highest in the fruits Chrysophyllum albidum (4.39\%) while only tannins ranged from o to $1.662 \mathrm{mg}$ per gram with $\mathrm{Mu}$ sanga leo-errerae containing the highest amount of tannins (Table 1).

The variation of the nutritional content of the most consumed fruits is 


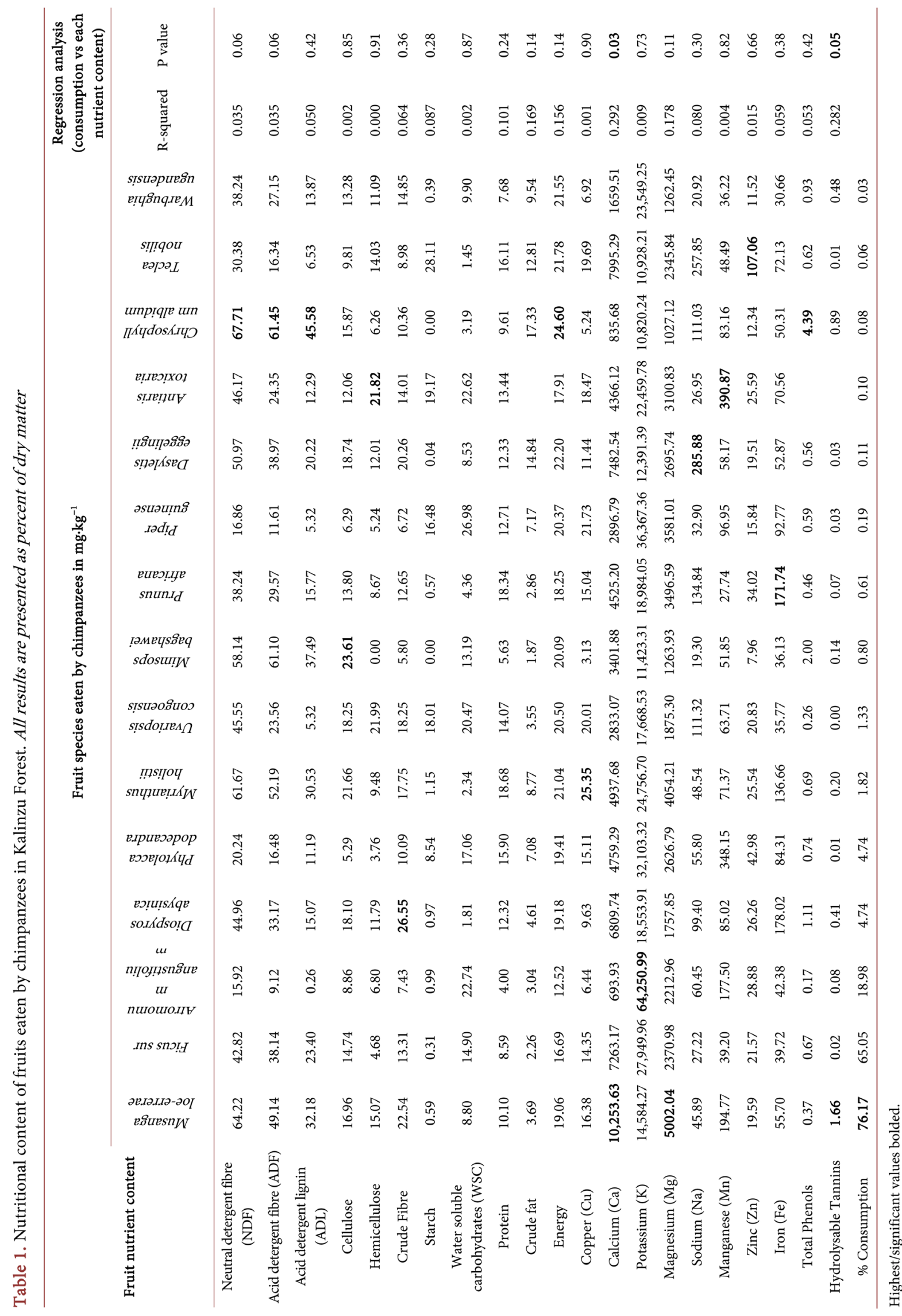


presented in Figure 2. Notable are the high amount of fibre, energy and tannin content in Musanga leo-errerae, fibre and energy in Ficus sur and water-soluble carbohydrates in Aframomum angustifolium; and the mineral content of calcium, potassium and magnesium in all the three.

\subsection{Nutritional Content and Its Influence on Consumption of Fruits Eaten by Chimpanzees}

Pearson's correlation coefficients ( $\mathrm{r}$ ) for food Consumption and nutritional contents revealed moderately to strongly positive correlations of glucose $(\mathrm{r}=0.51, \mathrm{P}$ $=0.069)$, tannins $(0.54, \mathrm{P}=0.069)$ and calcium $(\mathrm{r}=0.6, \mathrm{P}=0.026)$. This was tested with the WSC broken down to its constituents of glucose, fructose and sucrose. Multiple linear regression of these correlated food contents (Ca, glucose and tannins) as predictor variables with food consumption as the dependent variable is indicated in Table 2 . It shows that glucose and tannins had a significant contribution to food consumption at $5 \%$ level of significance while calcium did not have a significant effect on food consumption. Glucose has a higher contribution on food consumption $(\beta=0.615)$ than tannins $(\beta=0.535)$. Higher tolerance values of the predictor variables $(\mathrm{Ca}=0.812$, glucose $=0.921$, tannins $=$ 0.768 ) indicate weak relationship between the predictor variables themselves.

Nutrient contents' influence on consumption was again tested by multiple regression with the WSC combined as one. Figure 3 and Figure 4 show some of

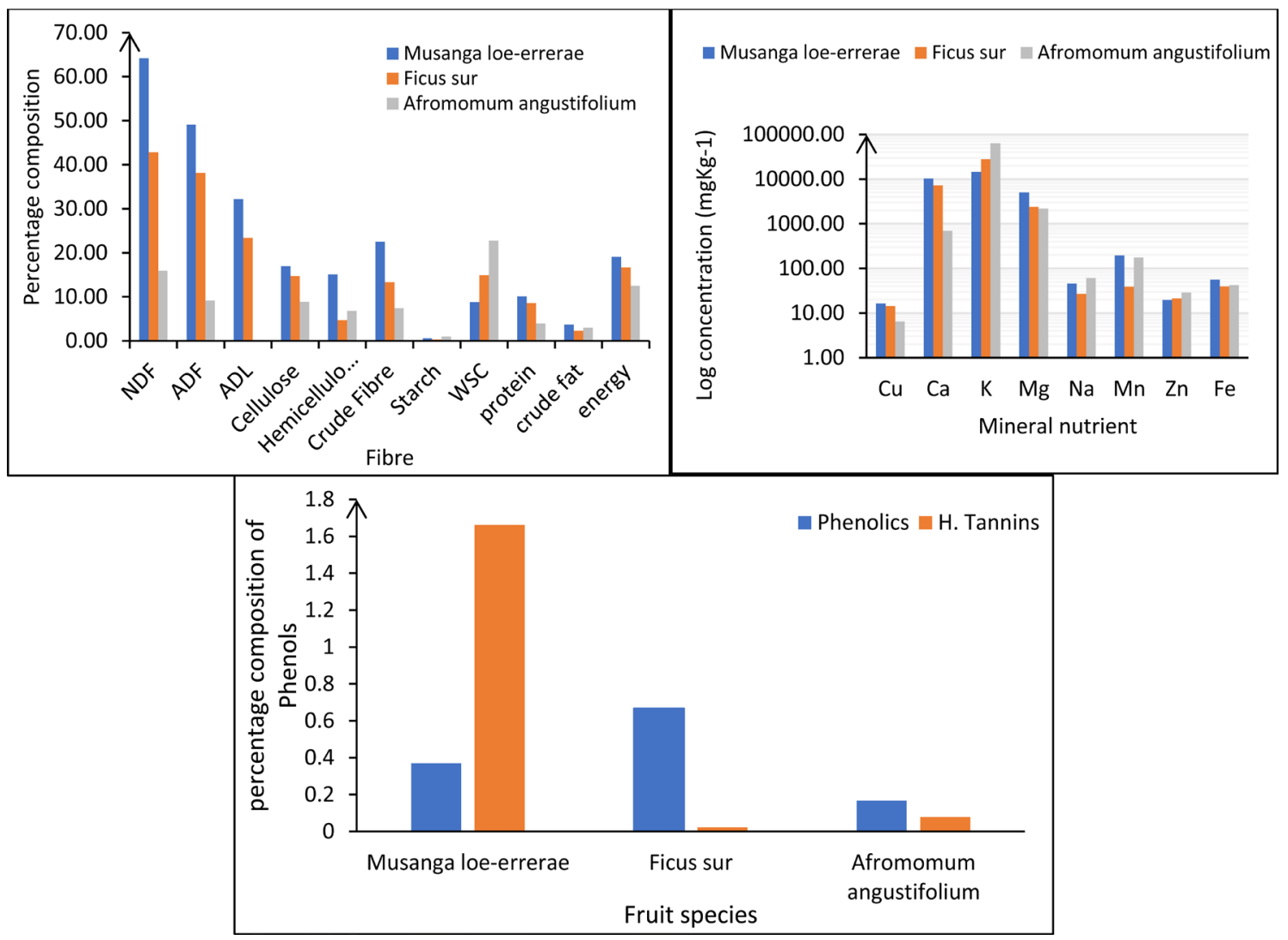

Figure 2. The nutritional content of the most consumed fruits consumed by Chimpanzees in Kalinzu Forest Reserve. 
Table 2. Multiple linear regression of positively correlated fruit nutrient content versus consumption.

\begin{tabular}{ccccccc}
\hline \multirow{2}{*}{ Model } & \multicolumn{2}{c}{ Unstandardized Coefficients } & $\begin{array}{c}\text { Standardized } \\
\text { Coefficients }\end{array}$ & $\mathbf{t}$ & Sig. \\
\cline { 2 - 4 } & B & Std. Error & Beta & & \\
\hline (Constant) & -30.413 & 8.859 & & -3.433 & 0.009 \\
Ca & 0.003 & 0.002 & 0.371 & 2.277 & 0.052 \\
glucose & 5.751 & 1.432 & 0.615 & 4.016 & 0.004 \\
Tannins & 28.553 & 8.942 & 0.535 & 3.193 & 0.013 \\
\hline
\end{tabular}

a. Dependent Variable: Consumption.
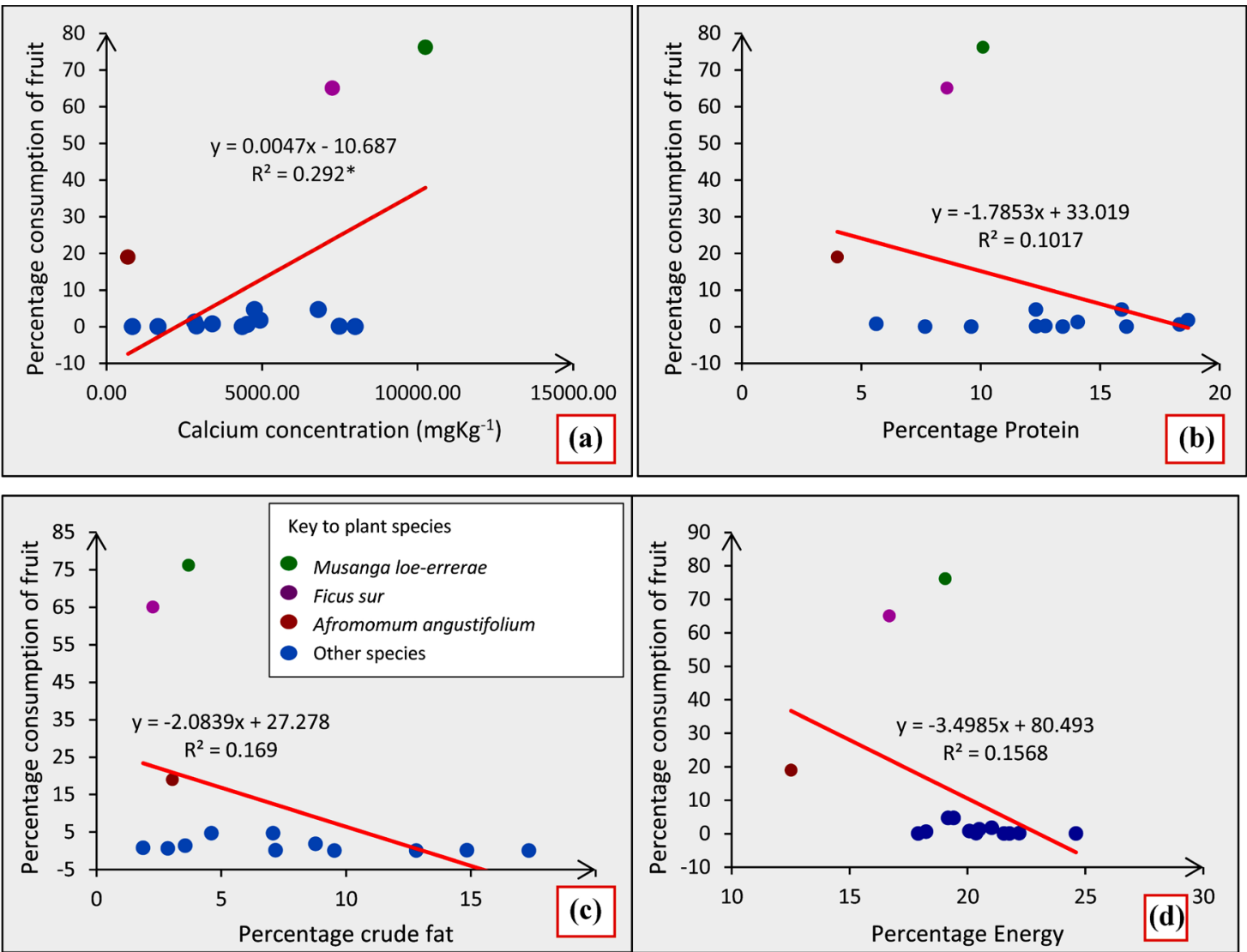

Figure 3. Relationship between percentage fruit consumption and the some of the most important nutrient constituents that predict consumption ( ${ }^{*}$ indicates significant $\mathrm{P}$ values).

the most important nutrient constituents of the fruits that predict consumption. The overall regression correlation of fruit consumption with the nutritional contents of fruit revealed that the basis for consumption was calcium and tannins since significant regression was exhibited at 0.05 level of significance. 29.2\% consumption $\left(R^{2}\right)$ is explained by Calcium $(P=0.03$, Figure $3(a))$, while tannins explain $28.3 \%$ consumption $\left(\mathrm{R}^{2}\right)$ (Figure $4(\mathrm{~b}), \mathrm{P}=0.050$ ). Though not statistically significant individually, other physicochemical parameters that explained consumption by more than $10 \%$ were protein $10 \%$ consumption (Figure $3(\mathrm{~b})$ ), 


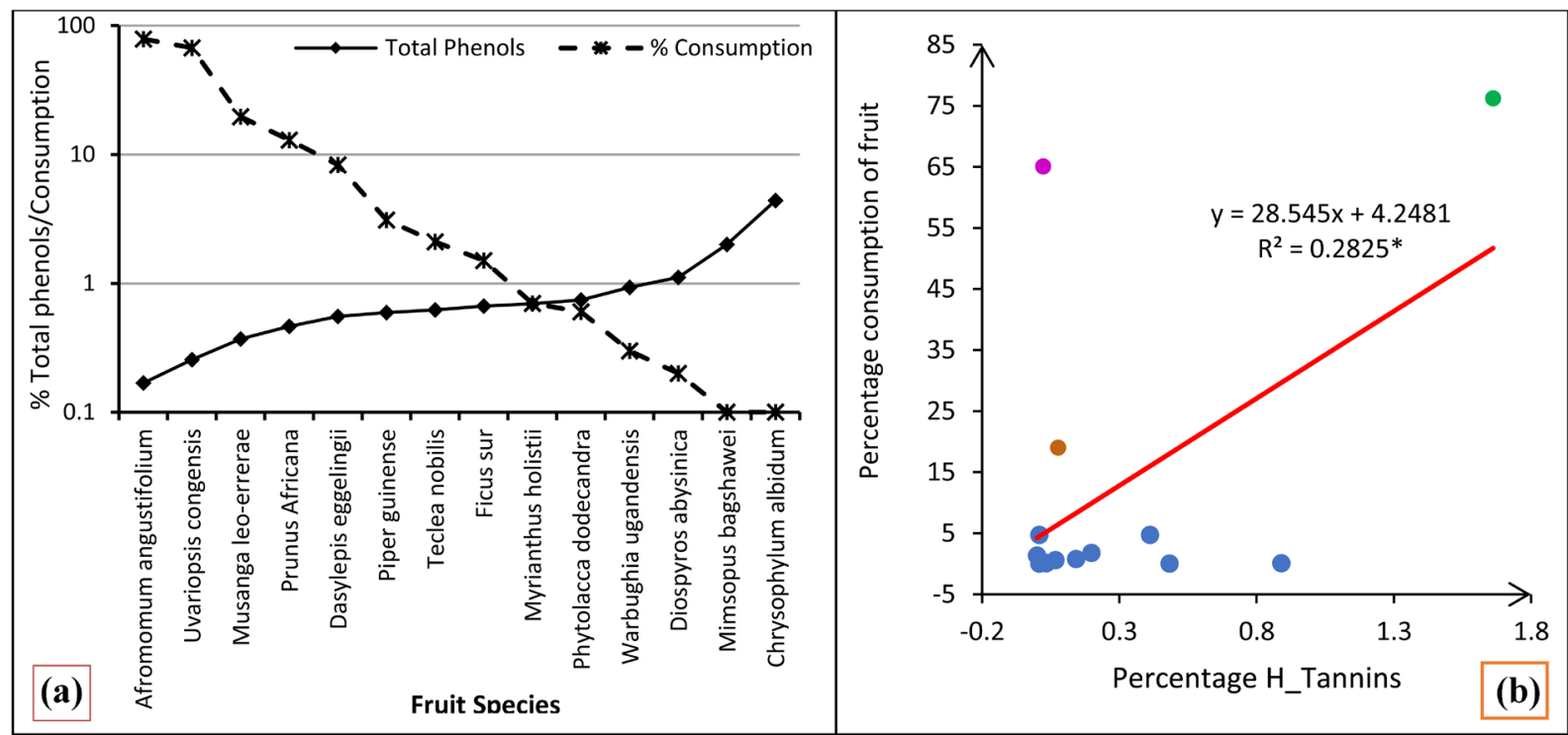

Figure 4. Relationship between total Phenols (a) Tannins (b) with Fruit consumption ( ${ }^{*}$ indicates P significant values).

$16.9 \%$ consumption by crude fat (Figure $3($ c) ), 15.6\% consumption by energy (Figure 3(d)) while $17.9 \%$ consumption was explained by Magnesium. While considering total phenols, consumption generally decreases with increase in phenolics except for fruits like Aframomum angustifolium, Uvariopsis congoensis, Musanga leo-errerae and Prunus Africana. Consumption tends to increase for fruits with total phenols below $1 \%$ per gram (Figure 4(a)).

By testing different models using different combinations of the nutritional parameters so as to see which combination explains consumption most, of the 15 nutrient parameters investigated, only Calcium, Tannins, crude fat, protein and energy content of the fruits explained $10 \%$ or more of the consumption of the fruits individually. The best multiple linear regression model was of the five parameters that significantly predicted $76.86 \%$ of consumption $\left(\mathrm{R}^{2}=76.86 \% ; \mathrm{p}=\right.$ $0.019)$. The best nutrient content that predicts consumption is as shown below.

$$
\begin{aligned}
\text { Consumption } & =70.189+0.004 \text { Calcium }+22.865 \mathrm{H} \text { Tannins } \\
& -1.252 \text { Protein }-3.382 \text { Energy }-0.456 \text { Crude fat }
\end{aligned}
$$

In this model, based on the magnitude of probability of predicting consumption (p-values), the relative importance of the nutrient parameter is Calcium > Tannins $>$ Energy $>$ Proteins $>$ Crude fat.

\section{Discussions}

Tropical forests inhabited by chimpanzees like Kalinzu are so diverse and each potential food item has its own distinctive combination of essential nutrients, fibre, and secondary compounds. The nutrient combinations of various fruits provide the dietary needs of chimpanzees in Kalinzu. Musanga leo-errerae, a fall-back food and Ficus spp. provides adequate nutrients of energy, fibre especially the NDF, and minerals like calcium, magnesium and manganese since they are the most consumed especially during the time of food scarcity. NDF provides 
high levels of energy in form of fermentable fibre; hence the importance of $M u^{-}$ sanga leo-errerae in chimpanzee diet which also agrees with the same hypothesis as set by [15] that fibre is an important dietary constituent of chimpanzees.

The level of influence of these nutritional variables on fruit choice can be complex. In this study, glucose, tannins and calcium concentrations tend to influence fruit consumption. Water soluble carbohydrates especially glucose may positively influence fruit choice for consumption although there was a weak positive correlation that was not found significant in this study. However, there is ample evidence that foraging and food selection by primates and other frugivorous vertebrates is affected by sugar content of fruit [16] which increases with fruit ripening [17]. The sweeter the food is, the more it tends to be eaten.

The best model that explained consumption significantly presented calcium followed by tannins then energy, proteins and fat. Although Waterman [18] stated that the choice of herbs in Mountain Gorillas was negatively influenced by condensed tannins, a notable exception is the positive correlation between tannins and consumption for the chimpanzee in Kalinzu especially Musanga leo-errerae fruit which was consumed highest and yet contained the greatest amount of tannins. It is not certain however, whether this same relationship between consumption and tannins occurs in other chimpanzee habitats where Musanga leo-errerae fruit does not occur. It is also important to discover what effects the high content of tannins in this fruit has on the digestion and absorption of other nutrients. Tannins have been documented to cause precipitation of some proteins and to have negative effects on the symbiotic organisms in the rumen some of which may be important for digestion [19]. Therefore, naturally occurring antimicrobial constituents of diet like tannins may affect occurrence of microbial composition in the digestive system; hence affecting digestive efficiency, nutrient delivery and health of chimpanzees.

From this study, however, the fruits with the high protein content had the lowest amount of tannins. Hence tannins negatively influencing consumption of fruits with high protein would not be expected except where such fruits are eaten in combination with fruits of high tannin content. However, if protein rich fruits are eaten in isolation, chimpanzees would not lose out on the moderate protein content since studies have noted that fruits do not seem to provide a high content of protein for the chimpanzees like leaves do in other primates.

The fact that some of the most eaten fruits like Aframomum angustifolium and Musanga leo-errerae were recorded to have the highest amounts in tannins shows that there must be other factors into play other than nutrient content as also explained by [20]. In other words, although Musanga leo-errerae had the highest amount of tannins, this did not deter the chimpanzees from eating it in great amounts. It is a possibility that the availability of Musanga leo-errerae as explained in [7] may override the presence of tannins to explain its great choice for consumption. Secondly, Musanga and Ficus fruit, the most consumed as per [21], have almost the same size (approximately $3 \mathrm{~cm}$ diameter) which may 
present an optimum size for easy and quick harvesting and bite efficiency ensuring food acquisition efficiency and favouring other activities like ranging as indicated in [22]., resting and eventual health of chimpanzees. Therefore, consideration of effect of fruit size and handling within the existing models of chimpanzees' diet could hence enhance further the understanding of fruit choice for consumption. It is also important to determine how this model of nutrient content works with seasonal fruit availability to influence fruit consumption. From this study, it is speculated that sugars may influence fruit choice only when fruit availability is high.

Results from this study suggest that chimpanzees of Kalinzu forest are exposed to a variety of macronutrients offered by fruit species. They consume fruits high in Calcium and vitamins, and their daily intake of calcium must be higher than the recommended $1000 \mathrm{mg}$ for human adults [23]. According to this study, Musanga leo errerae alone provides 10,253 mg per kilogram consumed per day. Therefore, Chimpanzees in Kalinzu forest must have adequate calcium intake and the benefits that come with it like strong bones and teeth.

The most determinants of consumption at $76.8 \%$ included calcium, protein, energy, fat and tannins that constitute the major food components an animal needs for energy giving, healthy skeleton and body building. Therefore, chimpanzees in Kailinzu are not losing out on any essential nutrients. Coupled with other fruits not analysed in this study, supplementary food nutrients like animal matter, leaves as documented in [24], or herbs as documented in [25], presents a rich and healthy diet for their diet.

\section{Acknowledgements}

This research was financed by DAAD and laboratory analysis done at the Leibniz Institute for Zoo and Wildlife, to whom I'm very grateful. I'm also very grateful to my host supervisor Dr. Sylvia Ortmann and Ms. Heidrun Barleben for all the support and technical guidance and Mr. Tumusiime Julius for data analysis. I would like to thank the Uganda National council for Science, National Forest Authority and Mbarara University of Science and Technology for the permission to work in Kalinzu forest to undertake this research.

\section{Conflicts of Interest}

The author declares no conflicts of interest regarding the publication of this paper.

\section{References}

[1] Fashing, P.J., Dierenfeld, E.S. and Mowry, C.B. (2007) Influence of Plant and Soil Chemistry on Food Selection, Ranging Patterns, and Biomass of Colobus guereza in Kakamega Forest, Kenya. International Journal of Primatology, 28, 673-703. https://doi.org/10.1007/s10764-006-9096-2

[2] Felton, A.M., Felton, A. and Raubenheimer, D. (2009) Protein Content of Diets Dictates the Daily Energy Intake of a Free-Ranging Primate. Behavioral Ecology, 20, 
685-690. https://doi.org/10.1093/beheco/arp021

[3] Matsumoto-Oda, A. and Hayashi, Y. (1999) Nutritional Aspects of Fruit Choice by Chimpanzees. Folia Primatologica, 70, 154-162. https://doi.org/10.1159/000021688

[4] Milton, K. (1999) Nutritional Characteristics of Wild Primate Foods: Do the Diets of Our Closest Living Relatives Have Lessons for Us? Nutrition, 15, 488-498. https://doi.org/10.1016/S0899-9007(99)00078-7

[5] Joanna, E. Lambert and Jessica, Rothman, M. (2015) Fallback Foods, Optimal Diets, and Nutritional Targets: Primate Responses to Varying Food Availability and Quality. Annual Review of Anthropology, 44, 493-512. https://doi.org/10.1146/annurev-anthro-102313-025928

[6] Rothman, J.M., Plumptre, A.J., Dierenfeld, E.S. and Pell, A.N. (2007) Nutritional Composition of the Diet of the Gorilla (Gorilla beringei): A Comparison between Two Montane Habitats. Journal of Tropical Ecology, 23, 673-682. https://doi.org/10.1017/S0266467407004555

[7] Kagoro-Rugunda, G. and Hashimoto, C. (2015) Fruit Phenology of Tree Species and Chimpanzees' Choice of Consumption in Kalinzu Forest Reserve, Uganda. Open Journal of Ecology, 5, 477-490. https://doi.org/10.4236/oje.2015.510039

[8] Howard, P.C. (1991) Nature Conservation in Uganda's Tropica Forest Reserve. IUCN, Gland, Switzerland, 313 p.

[9] Hashimoto, C., Furuichi, T. and Tashiro, Y. (1999) Diversity in Forest Types and Habitat Use by Chimpanzees in the Kalinzu Forest, Uganda. Primate Research, 15, 129-134. https://doi.org/10.2354/psj.15.129

[10] Plumptre, A.J., Cox, D. and Mugume, S. (2003) The Status of Chimpanzees in Uganda. Albertine Rift Technical Report Series No. 2. Wildlife Conservation Society, New York.

[11] Official Methods of Analysis (1995) AOAC IN-TERNATIONAL. 16th Edition, Gaithersburg, MD, Sec. 33.2.11, Method 991.20 (2).

[12] VanSoest, P.J. (1982) Nutritional Ecology of the Ruminant: Ruminant Metabolism, Nutritional Strategies, the Cellulolytic Fermentation and the Chemistry of Forages and Plant Fibres. Cornell University Press, Ithaca, NY, 373 p.

[13] Haslam, E. (1989) Plant Polyphenols-Vegetable Tannins Revisited. Cambridge University Press, Cambridge, UK.

[14] Strasbourg, (2008) European Pharmacopoeia, Council of Europe, $6^{\text {th }}$ ed.

[15] Wrangham, R.W., Conklin, N.L. and Hunt, K.D. (1991) The Significance of Fibrous Foods for Kibale Forest Chimpanzees. Philosophical Transactions of the Royal Society of London. Series B: Biological Sciences, 334, 171-178. https://doi.org/10.1098/rstb.1991.0106

[16] Ungar, P. (1995) Fruit Preferences of Four Sympatric Primate Species in Ketambe, Northern Sumatra, Indonesia. International Journal of Primatology, 16, 221-245. https://doi.org/10.1007/BF02735479

[17] Prasanna, V., Prabha, T.N. and Tharanathan, R.N. (2007) Fruit Ripening Phenomena-An Overview. Critical Reviews in Food Science and Nutrition, 47, 1-19. https://doi.org/10.1080/10408390600976841

[18] Ganas, J., Ortmann, S. and Robbins, M. (2009) Food Choices of the Mountain Gorilla in Bwindi Impenetrable National Park, Uganda: The Influence of Nutrients, phenolics and Availability. Journal of Tropical Ecology, 25, 123-134. https://doi.org/10.1017/S0266467408005701

[19] Waterman, P.G., Choo, G.M., Vedder, A.L. and Watts, D.P. (1983) Digestibility, 
Digestion Inhibitors, and Nutrient of Herbaceous Foliage and Green Stems from an African Montane Flora and Comparison with Other Tropical Flora. Ecologia, 60, 244-249. https://doi.org/10.1007/BF00379527

[20] Bryson-Morrison, N., Beer, A., Soumah, A.G., Matsuzawa, T. and Humle, T. (2020) The Macronutrient Composition of Wild and Cultivated Plant Foods of West African Chimpanzees (Pan troglodytes verus) Inhabiting an Anthropogenic Landscape. American Journal of Primatology, 82, e23102. https://doi.org/10.1002/ajp.23102

[21] Kagoro-Rugunda, G. and Kayanja, F.I.B. (2011) Ficus sp. and Musanga leo-errerae: Coexistent Keystone Fruits for Chimpanzees in Kalinzu Forest. African Journal of Ecology, 49, 389-396. https://doi.org/10.1111/j.1365-2028.2011.01292.x

[22] Hohmann, G., Fowler, A., Sommer, V. and Ortmann, S. (2006) Frugivory and Gregariousness of Salonga bonobos and Gashaka Chimpanzees: The Abundance and Nutritional Quality of Fruit. In: Hohmann, G., Robbins, M.M. and Boesch, C., Eds., Feeding Ecology in Apes and Other Primates, Cambridge University Press, Cambridge, 123-159.

[23] Milton, K. (2003) Micronutrient Intake of Wild Primates: Are Humans Different. Comparative Biochemistry and Physiology Part A: Molecular \& Integrative Physiology, 136, 47-59. https://doi.org/10.1016/S1095-6433(03)00084-9

[24] Hohmann, G., Potts, K., N'Guessan, A., Fowler, A., Mundry, R., Ganzhorn, J.U. and Ortmann, S. (2010) Plant Foods Consumed by Pan: Exploring the Variation of Nutritional Ecology Across Africa. American Journal of Physical Anthropology, 124, 234-247. https://doi.org/10.1002/ajpa.21168

[25] Tashiro, Y., Furuichi, T. and Hashimoto, C. (1999) A Preliminary Report of the Feeding Ecology of Chimpanzees in Kalinzu Forest Reserve, Uganda: Faecal Analysis and Habitat Use. Primate Research, 15, 179-185.

https://doi.org/10.2354/psj.15.179 